\section{Relationship between homocysteine and non-dipper pattern in patients with type 2 diabetes mellitus}

\author{
Relação entre a homocisteína e a condicão não \\ dipper em pacientes com diabetes melito tipo 2
}

Serdal Korkmaz' , Abdulkerim Yilmaz², Gürsel Yildiz³ , Fatih Kiliçlii ${ }^{4}$, Serhat Içağasioğlu ${ }^{5}$

\begin{abstract}
Objective: The rate of reduction of nocturnal blood pressure (NBP) is lesser than normal in patients with type 2 diabetes mellitus (type $2 \mathrm{DM}$ ). Hyperhomocysteinemia $(\mathrm{HHC})$ disrupts vascular structure and function, no matter the underlying causes. The risk of development of vascular disease is greater in diabetic patients with hyperhomocysteinemia than in patients with normal homocystein levels. The aim of the study was to investigate whether there are differences of homocystein levels in dipper and non-dippers patients with type $2 \mathrm{DM}$. Subjects and methods: We compared 50 patients ( 33 females, 17 males) with type 2 DM and 35 healthy individuals ( 18 females, 17 males ) in a control group. Ambulatory blood pressure monitoring (ABPM) was performed and homocysteine levels were measured in all patients. Results: We found that the percentage of non-dipper pattern was $72 \%$ in patients with type $2 \mathrm{DM}$ and $57 \%$ in control group. In diabetic and control individuals, homocystein levels were higher in non-dipper (respectively $13.4 \pm 8.1 \mu \mathrm{mol} / \mathrm{L}$ and $11.8 \pm 5 \mu \mathrm{mol} / \mathrm{L}$ ) than in dipper subjects (respectively, $11.8 \pm 5.8 \mu \mathrm{mol} / \mathrm{L}$ and $10.1 \pm 4.2 \mu \mathrm{mol} / \mathrm{L}$ ), but there was no significant difference between the two groups (respectively, $p=0.545, p=0.294$ ). Conclusion: In both groups, homocystein levels were higher in non-dipper than in dipper participants, but there was no significant difference between the groups. High homocystein levels and the non-dipper pattern increases cardiovascular risk. Therefore, the relationship between nocturnal blood pressure changes and homocystein levels should be investigated in a larger study. Arq Bras Endocrinol Metab. 2012;56(5):285-90
\end{abstract}

\section{Keywords}

Homocystein; nocturnal blood pressure; non-dipper phenomenon; diabetes mellitus type 2

\section{RESUMO}

Objetivo: A taxa de redução da pressão arterial noturna (PAN) é menor em pacientes com diabetes melito tipo 2 (DM tipo 2). A hiper-homocisteinemia (HHC) perturba a estrutura e a função vascular, independentemente das causas subjacentes. $\mathrm{O}$ risco de desenvolvimento de doenças vasculares é maior em pacientes diabéticos com hiper-homocisteinemia do que em pacientes com níveis normais de homocisteína. $\mathrm{O}$ objetivo deste estudo foi investigar se há diferenças entre os níveis de homocisteína em pacientes com DM2 em condição dipper ou não dipper. Sujeitos e métodos: Comparamos 50 pacientes (33 mulheres, 17 homens) com DM tipo 2 e 35 indivíduos saudáveis (18 mulheres, 17 homens), usados como grupo controle. A monitorização ambulatorial da pressão arterial (MAPA) e os níveis de hemocisteína foram medidos em todos os pacientes. Resultados: Observamos que a porcentagem de não dipper foi de $72 \%$ em pacientes com DM tipo 2 e $57 \%$ no grupo controle. Em indivíduos diabéticos e controle, os níveis de homocisteína foram mais altos em indivíduos não dipper (respectivamente $13,4 \pm 8,1 \mu \mathrm{mol} / \mathrm{L}$ e $11,8 \pm 5 \mu \mathrm{mol} / \mathrm{L}$ ) do que em indivíduos dipper (respectivamente, $11,8 \pm 5,8 \mu \mathrm{mol} / \mathrm{L}$ e 10,1 $\pm 4,2 \mu \mathrm{mol} / \mathrm{L}$ ), mas não houve diferença significativa entre os dois grupos (respectivamente, $p=0,545, p=0,294$ ). Conclusão: Em ambos os grupos, os níveis de homocisteína foram mais altos nos indivíduos não dipper do que nos indivíduos dipper, mas não houve diferença significativa entre os grupos. Altos níveis de homocisteína e a condição não dipper aumentam o risco cardiovascular. Portanto, a relação entre as alterações da pressão arterial noturna e os níveis de homocisteína deve ser investigada em um estudo mais amplo. Arq Bras Endocrinol Metab. 2012;56(5):285-90
${ }^{1}$ Division of Hematology, Cumhuriyet University School of Medicine, Sivas, Turkey 2 Division of Gastroenterology, Gaziosmanpaşa University School of Medicine, Tokat, Turkey ${ }^{3}$ Clinic of Nephrology, Atatürk State Hospital, Zongudak, Turkey ${ }^{4}$ Division of Endocrinology, Cumhuriyet University School of Medicine, Sivas, Turkey ${ }^{5}$ Department of Internal Medicine, Cumhuriyet University School of Medicine, Sivas, Turkey
Correspondence to: Gürsel Yildiz

Meşrutiyet Mahallesi Huzur Sokak, 35

67030 - Zongudak, Türkiye drgursel@yahoo.com

Received on Aug/20/2011 Accepted on Dec/7/2011 


\section{INTRODUCTION}

In developed and developing countries, prevalence of diabetes mellitus (DM) has quickly increased due to rapid change in lifestyle. DM leads to endothelial dysfunction and accelerated atherosclerosis. In humans, blood pressure exhibits a circadian pattern: it is decreased by sleeping at night, and increased by waking at daytime. The presence of a decrease lower than $10 / 5 \mathrm{mmHg}$ or $10 \%$, or an increase in blood pressure during the night has been defined as "non-dipper pattern or phenomenon" $(1,2)$. The non-dipper pattern is observed in about $25 \%$ of the hypertensive patients. In diabetic subjects, prevalence of this pattern is higher (3). In non-dipper hypertensive patients, target organ damage is more common. Numerous clinical studies have revealed that cardiovascular events are frequent in the early morning $(4,5)$. It is presumed that the non-dipper pattern may lead to this condition as well as many other factors such as platelet aggregation and increased plasma catecholamine levels (6).

Homocystein (Hcy) is sulfide amino acid that results from the methionine to cysteine transformation, and previous studies have detected that higher homocysteine is a risk factor for coronary, cerebral and peripheral vascular diseases (7). Hcy level is increased when there is deficiency of enzymes (cystathionine synthase or methyl tetrahydrofolate reductase) or cofactors (folic acid, vitamin B12) in the Hcy metabolism; high deficiency of methionine or vitamin B12 in the diet; senility and renal function impairment (811). Free radicals arise from accumulation and oxidation of Hcy in several tissues, and lead to endothelial dysfunction. Homocystein metabolites are attached to LDL (low-density lipoprotein), inducing LDL aggregation. Phagocytosis of LDL-thiolactone aggregates by intimal macrophages creates foam cells. As a result of these effects, Hcy leads to atherosclerotic plaques, vascular calcification, and fibrosis $(12,13)$. High levels of Hcy are especially observed in patients with complicated diabetes. Previous clinical studies have reported that there were significant reductions in systolic and diastolic blood pressure following minimization of Hcy levels. We aimed at examining the relationship between NBP changes and Hcy levels in type 2 diabetic patients, according to data in the literature.

\section{MATERIAL AND METHODS}

\section{Selection of the patients}

Inclusion criteria were diagnosis of type $2 \mathrm{DM}$; absence of any cardiovascular events in the past; no symptoms of malabsorption or history of gastrectomy; no use of drugs that may affect plasma homocystein levels (e.g. methotrexate, carbamazepine, phenytoin, nitrous oxide, corticosteroids); absence of illnesses such as hypothyroidism, malignant and psychiatric diseases; no diagnosis of megaloblastic anemia and not being under treatment for this disorder; no chronic renal disease; no chronic liver disease; no heart failure; signed of informed consent form.

Fifty patients with type 2 DM (group of patients) and 35 healthy individuals (control group) were included in the study. The study population was evaluated by physical examination and anamnesis. Body mass index was calculated by the $\mathrm{kg} / \mathrm{m}^{2}$ formula after height was measured and individuals were weighted. Fasting blood glucose, vitamin B12, folic acid and Hcy levels were determined in fasting and two hours after breakfast for the postprandial blood glucose in blood samples collected in the morning. Blood pressure was recorded by ambulatory blood pressure monitoring (ABPM) during 24 hours.

\section{Homocystein}

The $5 \mathrm{cc}$ blood sample collected in vacutainer tubes with EDTA were used in the Hcy assay. Serum was separated in a centrifuge (Hettich Zentrifugen Universal 32 ). Serum samples were kept at $-20^{\circ} \mathrm{C}$ until the moment of analysis. Hcy levels were detemined by chemiluminescense using a Homocysteine kit (Abbot, Illinois, US) in Abbott AxSYM autoanalyzer.

\section{Vitamin B12 and folic acid}

Vitamin B12 levels were determined by means of enzyme immunoassay using AIA-PACK B12 kit in AIA-600 Tosoh autoanalyzer.

\section{Statistical analysis}

Data are expressed as mean \pm SD. Data were analyzed by Student's t test, Chi-square test, Mann-Whitney U test, and Pearson's correlation; p-values $<0.05$ were considered significant.

\section{RESULTS}

The baseline characteristics of the studied population are summarized in table 1. Duration of diabetes was 9.8 \pm 7 years in the group of patients. 
Table 1. Demographic, clinical characteristics and laboratory data of study population

\begin{tabular}{|c|c|c|c|}
\hline & $\begin{array}{c}\text { Patients } \\
\text { group } \\
(n=50) \\
\frac{n}{X} \pm S D\end{array}$ & $\begin{array}{c}\text { Control } \\
\text { group } \\
(\mathrm{n}=35) \\
\bar{X} \pm \mathrm{SD}\end{array}$ & $p$ value \\
\hline \multicolumn{4}{|l|}{ Demographics } \\
\hline Age (years) & $59 \pm 8$ & $58 \pm 8$ & NS \\
\hline Gender (F/M, n) & $33 / 17$ & $18 / 17$ & NS \\
\hline \multicolumn{4}{|l|}{ Clinical characteristics } \\
\hline DM Duration (years) & $9.8 \pm 7$ & - & - \\
\hline BMI $\left(\mathrm{kg} / \mathrm{m}^{2}\right)$ & $30.2 \pm 5.2$ & $29.1 \pm 3.4$ & NS \\
\hline Dipper/nondipper (n) & $14 / 36$ & $15 / 20$ & NS \\
\hline \multicolumn{4}{|l|}{ Laboratory data } \\
\hline FBG (mg/dL) & $177 \pm 73$ & $84 \pm 7$ & $p<0,05$ \\
\hline PBG (mg/dL) & $243 \pm 94$ & $105 \pm 18$ & $p<0.05$ \\
\hline HbA1c (\%) & $8.7 \pm 2$ & $5.3 \pm 0.4$ & $p<0.05$ \\
\hline Hcy ( $\mu \mathrm{mol} / \mathrm{L})$ & $12.3 \pm 6.5$ & $10.8 \pm 4.6$ & NS \\
\hline Mean day SBP (mmHg) & $126 \pm 18$ & $124 \pm 15$ & NS \\
\hline Mean day DBP (mmHg) & $77 \pm 11$ & $80 \pm 11$ & NS \\
\hline Mean night SBP (mmHg) & $121 \pm 18$ & $116 \pm 15$ & NS \\
\hline Mean night DBP (mmHg) & $73 \pm 10$ & $74 \pm 10$ & NS \\
\hline
\end{tabular}

BMI: body mass index; DBP: diastolic blood pressure; DM: diabetes mellitus; FBG: fasting blood glucose; F/M: female/Male; HbA1c: glycosylated hemoglobin; Hcy: homocysteine; NS: nonsignificant; PBG: postprandial blood glucose; SBP: systolic blood pressure; SD: standard deviation; $\overline{\mathrm{X}}$ : mean.

Table 2. The relationship between HbA1c levels and Hcy in the patients group

\begin{tabular}{lccc}
\hline HbA1c (\%) & $\mathbf{n}(\%)$ & $\begin{array}{c}\text { Hcy }(\boldsymbol{\mu m o l} / \mathbf{L}) \\
\mathbf{X} \pm \mathbf{S D}\end{array}$ & p value \\
\hline$\geq 8.0$ & $31(62)$ & $14.1 \pm 7.3$ & 0.059 \\
$<8.0$ & $19(38)$ & $11.2 \pm 5.8$ & \\
\hline
\end{tabular}

HbA1c: glycosylated hemoglobin; Hcy: homocysteine.
The dipper pattern was present in $14(28 \%)$ and non-dipper pattern was present in $36(72 \%)$ individuals of the group of patients. The dipper pattern was present in $15(43 \%)$ and non-dipper pattern was present in $25(57 \%)$ of the control individuals. There were no significant differences between the two groups $(\mathrm{p}>0.05)$.

In diabetic patients and the control group, respectively, the dipper pattern was present in $14(28 \%)$ and $15(43 \%)$ individuals, and the non-dipper pattern was present in $36(72 \%)$ and 20 (57\%) individuals, respectively. There was no significant difference between the two groups $(\mathrm{p}>0.05)$.

In the group of patients, who had worse glycemic control (HbAlc $\geq 8.0 \%$ ) showed higher, Hcy levels than subjects who had good glycemic control, but this difference had no statistical significance $(\mathrm{p}>0.05$; Table 2). Hcy levels in dipper and non-dipper subjects in the group of patients were higher than the control group, but this difference was not statistically significance ( $p>0.05)$. Hcy levels in non-dipper individuals in the group of patients and control group were higher than in dipper individuals, but this difference was not significant $(p>0.05$; Table 3$)$. In the group of patients, the relationship between Hcy levels and DM duration, fasting blood glucose and postprandial blood glucose levels were not significant $(\mathrm{p}>0.05)$. Both groups had normal vitamin $\mathrm{B} 12$ and folic acid levels.

\section{DISCUSSION}

High Hcy levels are independent risk factors for cardiovascular diseases, and it has a correlate with systolic and diastolic blood pressure and NBP changes. The

Table 3. Metabolic parameters of individuals with dipper and non-dipper in the study population

\begin{tabular}{|c|c|c|c|c|c|c|}
\hline & \multicolumn{3}{|c|}{ Patients group } & \multicolumn{3}{|c|}{ Control group } \\
\hline & $\begin{array}{c}\text { Dipper } \\
(n=14) \\
\bar{X} \pm S D\end{array}$ & $\begin{array}{c}\text { Non-dipper } \\
(\mathbf{n}=36) \\
\bar{X} \pm S D\end{array}$ & $p$ value & $\begin{array}{l}\text { Dipper } \\
(n=15) \\
\bar{X} \pm S D\end{array}$ & $\begin{array}{c}\text { Non-dipper } \\
(\mathbf{n}=\mathbf{2 0}) \\
\bar{X} \pm S D\end{array}$ & $p$ value \\
\hline BMI $\left(\mathrm{kg} / \mathrm{m}^{2}\right)$ & $31.1 \pm 5.7$ & $29.9 \pm 5.1$ & 0.456 & & $29.5 \pm 3.8$ & 0.342 \\
\hline DM duration (years) & $6.2 \pm 6.1$ & $10.2 \pm 7.4$ & 0.522 & - & - & - \\
\hline $\mathrm{FBG}(\mathrm{mg} / \mathrm{dL})$ & $182 \pm 93$ & $175 \pm 65$ & 0.837 & $85 \pm 7$ & $84 \pm 7$ & 0.570 \\
\hline PBG (mg/dL) & $239 \pm 109$ & $244 \pm 89$ & 0.689 & $110 \pm 26$ & $101 \pm 6$ & 0,764 \\
\hline HbA1c (\%) & $7.9 \pm 1.7$ & $9 \pm 2.1$ & 0.084 & $5.3 \pm 0.4$ & $5,4 \pm 0.4$ & 0.536 \\
\hline Hcy $(\mu \mathrm{mol} / \mathrm{L})$ & $11.8 \pm 5.8$ & $13.4 \pm 8.1$ & 0.545 & $10.1 \pm 4.2$ & $11.8 \pm 5$ & 0.294 \\
\hline
\end{tabular}

BMI: body mass index; DM: diabetes mellitus; FBG: fasting blood glucose; HbA1c: glycosylated hemoglobin; Hcy: homocysteine; PBG: postprandial blood glucose; SD: standard deviation; $\bar{X}$ : mean. 
non-dipper pattern is related with increased cardiovascular complications. Target organ damage in hypertensive patients correlated to a similar degree with daytime and nighttime blood pressure, on the basis of the observation that in hypertensive patients showing little or no nighttime blood pressure fall, end-organ damage is greater and cardiovascular events are more frequent than in hypertensive patients showing a clear nocturnal blood pressure fall (14). In conditions such as aging, some types of secondary hypertension (HT), Cushing syndrome, complicated DM with microalbuminuria, pheochromocytoma, renal parenchymal illness, eclampsia and congestive heart failure, it has been shown that the nocturnal reduction in blood pressure is lower than expected (15-17). Fogari and cols. compared 47 normotensive and 48 hypertensive diabetic patients with 103 healthy individuals and were unable to detect a decrease in NBP in $30 \%$ of the normotensive diabetics and in $31 \%$ of hypertensive patients (18). Bauduceau and cols. determined that 167 patients were non-dippers (34\%) and 317 were dippers $(65 \%)$ among 484 diabetic patients (19). Guerrero-Romero and cols. found nearly the same results in their studies (20). In our study, there were 36 non-dippers $(72 \%)$ in type 2 diabetic patients, and 20 ( 72.1\%) in the control group.

Hyperinsulinemia (21), autonomic neuropathy (22), and impaired sleep quality may cause nocturnal hypertension in type 2 DM. In addition, diabetic patients often wake up during the night because of nocturia and BP measurement every 15-30 minutes, which causes blood pressure changes and affect sleep quality (23). Because of this, some of patients may be erroneously considered be as non-dipper. However, ABPM equipment does not generally affect nocturnal blood pressure. When measuring BP, the position of the arm and body during sleep affects BP measurement. In theory, this situation may cause errors in the calculation of night-day BP differences. Because of this, classification in dipper or non-dipper should not rely solely on one ABPM measurement.

We found high rates of the non-dipper pattern in both groups. We think that problems such as disruption of sleep patterns, intensity of work during the day, BP measurement in an inadequate position, presence of autonomic neuropathy, nocturia, and adjustment problems in the use of ABPM equipment for the first time may have led to these higher rates observed in the present report with other studies.
In the last 10 years, lots of retrospective and prospective clinical studies $(9,10)$ about cardiovascular diseases showed that increased plasma Hcy levels are independent risk factor for cerebral and peripheral vascular illness, but recently Hcy levels have been replaced by cholesterol, smoking, and obesity (24). Nowadays, growing evidence froms epidemiological, animal and genetic studies showed that Hcy level is an etiologic factor in cardiovascular illness. Generally it is accepted that values higher than $14 \mathrm{mmol} / \mathrm{L}(25)$, and sometimes higher than $20 \mathrm{mmol} / \mathrm{L}$, pose the highest risk (26).

Chambers and cols. showed that an elevation in homocysteine concentration which is created with to drink oral methionine (metabolic precursor of homocysteine) is associated with an acute impairment of vascular endothelial function (27). Sutton-Tyrrell and cols. showed that high Hcy levels cause high systolic BP (28). Hcy decreases the relaxing factor produced by endothelial cells, induces muscle cell proliferation in blood vessels and reduces nitric oxide bioavailability, increases monocyte, neutrophil and platelet adhesion to endothelial cells, and leads to faster occurence of atherosclerosis, with increased cytotoxic affect (29).

We know that Hcy levels are higher in type $2 \mathrm{DM}$ patients $(30,31)$. In our study, we found Hcy levels even higher in the diabetic group than in the control group (respectively $12.3 \pm 6.5 \mu \mathrm{mol} / \mathrm{L}$ and $10.8 \pm 4.6$ $\mu \mathrm{mol} / \mathrm{L})$, but this difference had not statistical significance.

HHC is seen more often in patients with complicated diabetes, HT and nephropathy, than in patients with uncomplicated diabetes (32). Buysschaert and cols. found Hcy levels higher than $15 \mu \mathrm{mol} / \mathrm{L}$ in $31 \%$ of 122 complicated diabetic patients (33). We found Hcy levels higher than $15 \mu \mathrm{mol} / \mathrm{L}$ in $20 \%$ of the diabetic patients, but these patients were not evaluated for diabetic complications. Patients with cardiovascular disease and nephropathy were excluded from the study, and this may be a reason for reduced Hcy levels observed. In diabetic patients with $\mathrm{HHC}$, improvement in the risk of vascular disease is greater than in diabetic patients with normal Hcy levels, and this may lead to faster disease progression (34). Passaro and cols. showed that Hcy decreases with improved glycemic control (35). Pouwels and cols. reported that there is no difference in the improvement of glycemic control (36). In our study, we determined that Hcy levels were high in diabetic patients with worse glycemic control $(\mathrm{HbAlc} \geq$ $8 \%$ ), but this difference was not statistically significant. 
In some studies, it has been shown that HHC affects vascular functions. Tan and cols. showed that there were impairment of endothelium-dependent and -independent vasodilation was already present in diabetic patients with normal Hcy levels, and these abnormalities became more severe with increasing Hcy levels. (37). When nitric oxide (NO) levels are reduced, a small increase in Hcy leads to decrased residual $\mathrm{NO}$, which affects arterial regulatory tonus (38). Recently, a correlation between systolic BP and plasma Hcy levels has been shown in a hypertensive geriatric population (39). In the $3^{\text {rd }}$ National Health and Nutrition Examination Survey (NHANES III) study, increased BP prevalence was shown to be 2-3 times greater in individuals with high levels of Hcy than in individuals with lower Hcy levels (40). These investigations were corroborated with other experimental and cross-sectional studies.

In addition to the reduction in systolic and diastolic BP caused by Hcy lowering therapy, it was shown that Hcy has a role in the pathogenesis of high BP. Differently, Sundström and cols., at the end of a 4-year study with 2104 healthy individuals who joined the Framingham Heart Study found no relationship between baseline Hcy levels and incidence and progression of high BP (41). In our study, Hcy levels were higher in nondipper than in dipper individuals, but this finding was not statistically significant.

As a conclusion, we suggest that patients with type 2 DM should be better analyzed in terms of Hcy levels and nocturnal blood pressure changes, because hyperhomocysteinemia and the non-dipper pattern were observed more frequently in these patients. In this context, we think that the evaluation of non-dipper pattern and Hcy levels are important, and large-scale and detailed studies should be carried out to determine the relationship between these two factors.

Disclosure: no potential conflict of interest relevant to this article was reported.

\section{REFERENCES}

1. O'Brien E, Sheridan J, O'Malley K. Dippers and non-dippers. Lancet. 1988;2:397.

2. Verdecchia P, Schillaci G, Borgioni C, Ciucci A. White coat hypertension: not guilty when correctly defined. Blood Pres Monit. 1998;3:147-52.

3. PickeringTG, Kario K. Nocturnal non-dipping: what does it augur? Curr Opin Nephrol Hypertens. 2001;10 (5):611-6.

4. Marler JR, Price TR, Clark GL, Muller JE, Robertson T, Mohr JP, et al. Morning increase in onset of ischemic stroke. Stroke. 1989;20:473-6.
5. Willich SN, Goldberg RJ, Maclure M, Perriello L, Muller JE. Increased onset of sudden cardiac death in the first $3 \mathrm{~h}$ after awakening. Am J Cardiol. 1992;70:65-8.

6. Willich SN, Jimenez AH, Tofler GH, DeSilva RA, Muller JE. Pathophysiology and triggers of acute myocardial infarction: clinical implications. Clin Invest. 1992;70:73-8.

7. Temel I, Ozerol E. Homocysteine metabolism disorders and their relationship with vascular diseases. J Inonu Univ Med Facul. 2002;9(2):149-57.

8. Kang SS, Zhou J, Wong PW, Kowalisyn J, Strokosch G. Intermediate homocysteinemi a termdabile variant of metihylenetetra hydrofolate reductase. Am J Hum Genet. 1988;43:414-21.

9. Jakobsen DW. Homocysteine and vitamins in cardiovasculer disease. Clin Chem. 1998;44:1833-43.

10. Robinson K, Mayer E, Jacobsen DW. Homocysteine and coroner arter disease. Am J Cardiol. 1994;61:438-50.

11. Wu LL, Wu J, Hunt SC, James BC, Vincent GM, Williams RR, et al. Plasma homocysteine as a risk factor for early familial coronary arter disease. Clin Chem. 1994;40(4): 552-61.

12. Ebstein FH, Welch GN, Loscaizo J. Homocysteine and atherosclerosis. N Eng J Med. 1998;338(15):1042-49.

13. Shargorodsky M, Boaz M, Pasternak S, Hanah R, Matas Z, Fux A, et al. Serum homocysteine, folate, vitamin B12 levels and arterial stiffness in diabetic patients: which of them is really important in atherogenesis? Diabetes Metab Res Rev. 2009;25(1):70-5.

14. Mancia G, Zanchetti A, Agabiti-Rosei E, Benemio G, De Cesaris $\mathrm{R}$, Fogari $\mathrm{R}$, et al. Ambulatory blood pressure is superior to clinic blood pressure in predicting treatment-induced regression of left ventricular hypertrophy. SAMPLE Study Group. Study on Ambulatory Monitoring of Blood Pressure and Lisinopril Evaluation. Circulation. 1997;95(6):1464-70.

15. Zito M, Cervone C, Piersante P, Benigni DM, Parati G, Puddu GM, et al. Ambulatory blood pressure monitoring in elderly subjects with isolated systolic hypertension, essential hypertension, and normotension. High Blood Press. 1994;3:97-101.

16. Prinze PN, Vitiello MV, Raskind MA, Thorpy MJ. Geriatrics: sleep disorders and aging. N Eng J Med. 1990;323:520-5.

17. Coca A. Circadian rhythm and blood pressure control: physiological and pathophysiological factors. J Hypertens. 1994;12:13-21.

18. Fogari R, Zoppi A, Malamani GD, Lazzari P, Destro M, Corradi L. Ambulatory blood pressure monitoring in normotensive and hypertensive type 2 diabetes. Prevalence of impaired diurnal blood pressure patterns. Am J Hypertens. 1993;6(I):1-7.

19. Bauduceau B, Mayaudon H, Dupuy O, Palou M, Czerniak E, Bredin $C$, et al. The impact of dipper and non-dipper characteristics in the fluctuation of arterial blood pressure. A study of a population of 484 diabetic patients. Arch Mal Coeur Vaiss. 2000;93(8):969-73.

20. Guerrero-Romero F, Rodriguez-Moran M. Circadian arterial blood pressure variation in non hypertensive type 2 diabetic patients. Rev Invest Clin. 2000;52(5):517-23.

21. Cusaro C, Zamboni G, Chiarinotti D, Cadario F, Allochis G, Fortina $A$, et al. 24 hour arterial pressure in insulin-dependent diabetics and non-insulin-dependent diabetics with preserved renal function. Minerva Urologica Nefrologica. 1999;51:143-8.

22. Spallone V, Maiello MR, Cicconetti E, Pannone A, Barini A, Gambardella $S$, et al. Factors determining the 24-h blood pressure profile in normotensive patients with type 1 and type 2 diabetes. J Hum Hypertens. 2001;15(4):239-46.

23. Degaute JP, van de Borne $P$, Kerkhofs $M$, Dramaix M, Linkowski P. Does non-invasive ambulatory blood pressure monitoring disturb sleep? J Hypertens. 1992;10:879-85.

24. Eikelboom JW, Lonn E, Genest J Jr, Hankey G, Yusuf S. Homocysteine and cardiovascular disease: a critical review of the epidemiologic evidence. Ann Intern Med. 1999; 131:363-75. 
25. Nygard O, Nordrehaug JE, Refsum H, Ueland PM, Farstad M, Vollset SE. Plasma homocysteine levels and mortality in patients with coronery artery disease. N Engl J Med. 1997;337:230-6.

26. Moat SJ, Bonham JR, Powers HJ. Roal of aminothiols as a component of the plasma antioxidant system and relevance to homocysteine-mediated vascular disease. Clin Sci. 2001;100:73-9.

27. Chambers JC, McGregor A, Jean-Marie J, Obeid OA, Kooner JS. Demonstration of rapid onset vascular endothelial dysfunction after hyperhomocysteinemia: an effect reversible with vitamin $\mathrm{C}$ therapy. Circulation. 1999;99:1156-60.

28. Sutton-Tyrrell K, Bostom A, Selhub J, Zeigler-Johnson C. High homocysteine levels ar independently related to isolated systolic hypertension in older adults. Circulation. 1997;96:1745-49.

29. Havranek FP. Primary prevention of cardiovascular disease. Nine ways to reduce risk. Am Pam Physician.1999;59:1455-63.

30. Chico A, Pérez A, Córdoba A, Arcelús $R$, Carreras $G$, de Leiva A, et al. Plasma honocysteine is related to albumin excretion rate in patients with diabetes mellitus: a new link between diabetic nephropathy and cardiovascular disease. Diabetologia. 1998;41:684-93.

31. Ndrepepa G, Kastrati A, Braun S, Koch W, Kölling K, Mehilli J, et al. Circulating homocysteine levels in patients with type 2 diabetes mellitus. Nutr Metab Cardiovasc Dis. 2008;18(1):66-73.

32. Gu W, Lu J, Yang G, Dou J, MuY, Meng J, et al. Plasma homocysteine thiolactone associated with risk of macrovasculopathy in Chinese patients with type 2 diabetes mellitus. Adv Ther. 2008;25(9):914-24

33. Buysschaert M, Dramais AS, Wallemacq PE, Hermans MP. Hyperhomocysteinemia in type 2 diabetes: relationship to macroangiopathy, nephropathy, and insulin resistance. Diabetes Care. 2000;23(12):1816-22.
34. Hoogeveen EK, Kostense PJ, Beks PJ, Mackaay AJ, Jakobs C, Bouter LM, et al. Hyperhomocysteinemia is associated with an increased risk of cardiovascular disease, especially in non-insulin dependant diabetes mellitus: a population-based study. ArteriosclerThromb Vase Biol. 1998;18:133-8.

35. Passaro A, Calzoni F, Volpato S, Nora ED, Pareschi PL, Zamboni PF, et al. Effect of metabolic control on homocysteine levels in type 2 diabetic patients: a 3-year follow-up. J Intern Med. 2003;254:264-71.

36. Pouwels MJJ, den Heijer M, Blom HJ, Tack CJ, Hermus AR. Improved insulin sensitivity and metabolic control in type 2 diabetes does not influence plasma homocysteine. Diabetes Care. 2003;26:1637-9.

37. Tan KC, O K, Chow WS, Ai VH, Siow YL, Lam KS. Hyperhomocysteinemia and impaired vasomotor function in type 2 diabetes mellitus. Eur J Clin Invest. 2002;32:328-34.

38. Fiorina P, Lanfredini M, Montanari A, Peca MG, Veronelli A, Mello $A$, et al. Plasma homocysteine and folate are related to arterial blood pressure in type 2 diabetes mellitus. Am J Hypertens. 1998;11(9):1100-7.

39. Tyrrell KS, Bostom A, Selhub J, Johnson CZ. High homocysteine levels are independently related to isolated systolic hypertension in older adults. Circulation. 1997;96:1745-9.

40. Lim U, Cassano PA. Homocysteine and blood pressure in the Third National Health and Nutrition Examination Survey, 19881994. Am J Epidemiol. 2002;156:1105-13.

41. Sundström J, Sullivan L, D'Agostino RB, Jacques PF, Selhub $\mathrm{J}$, Rosenberg $\mathrm{IH}$, et al. Plasma homocysteine, hypertension Incidence, and blood pressure tracking: The Framingham Heart Study. Hypertension. 2003;42:1100-5. 